\title{
MEMORIA Y ORALIDAD: FORMAS DE ENTENDER EL PASADO DESDE EL PRESENTE*
}

\author{
MEMORY AND ORALITY: WAYS TO UNDERTAND THE PAST \\ FROM THE PRESENT
}

\author{
María Esperanza Rock Núñez ${ }^{* *}$
}

\begin{abstract}
Este artículo presenta reflexiones en torno al uso de la memoria y oralidad en estudios culturales e históricos, abordados desde una óptica interdisciplinaria e integrativa.

Se revisarán algunas nociones en relación con la oralidad, memoria y cultura para posteriormente indagar en tácticas metodológicas tendientes a extraer de la memoria y oralidad datos importantes para la reconstrucción del pasado en un intento por hacer una historia representativa.
\end{abstract}

Palabras claves: Memoria, oralidad, identidad, local, cultura.

This article present reflections attempting to use the memory and orality in cultural and historical studies, understanding by an integrative and interdisciplinary view.

Will review some notions in relation to orality, memory and culture to further investigate using methodological tactics tending to draw from memory and orality important data for the reconstruction of the past in an attempt to make a representative history.

Key words: Memory, orality, identity, local, culture.

\section{Introducción}

Las Ciencias Humanas han tendido hacia la integración interdisciplinaria para dar respuesta a cuestiones que pocas veces son resueltas desde una sola disciplina. La etnohistoria como ciencia ha abierto líneas de investigación particulares en relación con el pasado indígena y en ella se vislumbra la necesidad de crear métodos investigativos en función a las exigencias de los casos de estudio, volcando muchas veces la mirada hacia lo local, lo cultural y al grupo humano en específico.

En relación con esto es que la evolución de la metodología en las ciencias históricas -sobre todo en temas indígenas- ha centrado sus energías en la búsqueda permanente de diversos puntos de vistas que diluciden eventos históricos relevantes para comprender la formación de las culturas y sociedades.

Es en esta dirección que planteamos para este artículo una reflexión en torno a la metodología de investigación, específicamente en el uso de la memoria y la oralidad como fuentes documentales veraces, que ayudan tanto a dilucidar vacíos históricos como a complementar o simplemente redefinir la interpretación de la documentación de época. Con la inclusión de este tipo de documentos, muchas veces "no escritos", el análisis de sistemas simbólicos desde su pasado, comprendiendo su entramado sociocultural a lo largo del tiempo y el resultado que de este podemos observar en la actualidad, se vuelve un objetivo fascinante que detona un sinnúmero de posibles estudios.

Es en la memoria donde residen los imaginarios que contemplamos como identidades en la actualidad, las que lejos de ser poéticas del pasado, son el resultado de diversas imbricaciones culturales y eventos históricos que un grupo humano experimentó a lo largo del tiempo, que nos entregan información invaluable para comprender la toma de decisiones, la mentalidad y las formas de relacionarse, estas por lo general se mantienen en esencia hasta en la actualidad. Es ahí donde reside la importancia de su revisión y la validez de su estudio, el problema es saber cómo estudiarlo y desde dónde comenzar, para ello utilizaremos este espacio de reflexión.

Primero revisaremos qué es lo que se entiende por oralidad y memoria. Posteriormente examinaremos algunos conceptos para comprender el rol de la oralidad en la cultura e historia. Luego de establecidos los parámetros teóricos, observaremos

\footnotetext{
* Resultado de Proyecyo CONICYT N 15510545 y con el patrocinio de la Universidad de Chile.

** Universidad San Sebastián, sede res Pacualas, Concepción, Chile. Correo electrónico: esperanzarock@ gmail.com
} 
la importancia de reducir el campo de investigación a lo local y desde ahí evaluar la importancia que la memoria y oralidad tienen en la construcción del pasado, en la revisión documental de época y en el cómo podemos revisar el pasado desde el presente comprendido desde sus propios actores, en un intento de generar un espacio de representatividad histórica o más bien de historia representativa desde y en localidades específicas.

Hemos de entender de antemano que posiblemente necesitemos seguir indagando en esta temática, y lo que este artículo ofrezca sea solo el esbozo de una idea metodológica "aplicable" a lugares específicos con elementos particulares. No obstante ello, pensar en esto nos obliga a revisar y resituarnos en el constante desafío de conocer el pasado, comprenderlo y reflexionar respecto de nuestro presente.

\section{Lo oral como canal de la memoria y permanencia}

La memoria es uno de los espacios más importantes en el momento de pensar la historia y la cultura. En ella habitan los cimientos de cualquier conocimiento, además de una temporalidad, atemporalidad o simultaneidad que estará jerárquicamente organizada, ya sea por interés del individuo o del grupo como de quienes la estudien. Este archivo (memoria) tiene conocimientos aprendidos por diversos medios. Los que más reconocemos son: la observación, desde lo auditivo o desde el aprendizaje directo guiado.

Las formas de almacenamiento del conocimiento adquirido son también variadas y transitan desde lo individual a lo grupal, pues existen prácticas de comportamiento que son más o menos general para todas las personas que viven en comunidad. Estas se vinculan directamente al modo de relacionarse y de vivir bajo consensos adquiridos para, de alguna manera, mantener una unión constante. Desde allí surgirían entonces los juicios de lo que es bueno y malo, ya que en función a ellos se formaría el criterio de ética y moral.

Esto está permeado además con la visión de mundo del grupo humano, es decir, con la concepción de lo religioso como una elaboración cultural que tiene por objetivo formar un sistema de representación de lo sagrado. Es desde allí donde proliferan imaginarios religiosos que han de representar un significado particular para quienes logren comprender e interiorizar la manera ética, moral y afectiva de los significados que se vinculan, por lo general, a menciones metafísicas, las que queramos o no, modelan en alguna medida las conductas de vida.

Comúnmente todo esto se archiva y articula en la memoria, donde no solo está el conocimiento, sino que también el quehacer, la realidad, las formas, las maneras, los significantes del sistema simbólico y desde donde se definirían los dinamismos socioculturales.

Los canales de trasmisión se pueden vincular a la tradición; entendiendo esta como un puente que transporta el conocimiento de generación en generación; en este caso podemos decir que es un puente que traspasa archivos de la memoria. Esto por lo general se realiza desde diversos canales; sin embrago en el mundo occidental lo más frecuente es la trasmisión vía lenguaje (verbal), sea oral o escrito.

Se debe aclarar que las tradiciones no siempre tienen orígenes antiguos, puede ser que nos encontremos también con tradiciones recientes y que también logren un impacto cultural importante y perduren en el tiempo ${ }^{1}$. Muchas veces nos topamos con que las tradiciones orales carecen de un origen temporal claro, lo que ha hecho que por años estas no sean consideradas fidedignas o veraces, sin embargo, estas pueden enriquecer de manera sustancial el discurso histórico de una localidad como analizaremos en adelante.

Lo interesante es observar cómo los testimonios orales nos ayudan a entender el sistema cultural de un grupo humano, y cómo mediante ellos podemos releer o resignificar los datos documentales existentes, para posteriormente levantar un sistema de interpretación y análisis que posiblemente esté más cercana a lo que denominamos historia representativa, es decir, una historia más cercana a los habitantes de la localidad, dado que se incorporarían datos más familiares, anécdotas y saberes colectivos desde su propia significancia, no desde la óptica del observador. En definitiva se convierten en datos afectivos y tremendamente valorables por la localidad en general, ya que demuestra una identidad propia.

En el último siglo las nociones de lo oral en las Ciencias Históricas han ido tomando importancia. Poco a poco los prejuicios de veracidad que sufrían los testimonios se han ido paulatinamente atenuando debido a las nuevas corrientes historiográficas y las nuevas tácticas metodológicas ${ }^{2}$. 
Se sabe que la inclusión de lo oral en su generalidad deviene del cambio disciplinar que sufre la historiografía, por sobre todo con la historia social ${ }^{3}$. Pero más que buscar el origen temporal de la historia oral ${ }^{4}$, queremos entender sus alcances y en este sentido no podemos dejar de mencionar a algunos autores que, a propósito de los estudios realizados en África, se acercan a la oralidad para incorporar datos al discurso histórico, por sobre todo para indagar en la historia de los originarios. En torno a esto existen variadas e importantes discusiones, y en esta ocasión no indagaremos mucho en ellas, dado el enfoque de este artículo, no obstante es preciso considerar los procesos sociales, culturales y políticos que ha vivido el viejo continente para comprender la importancia de la oralidad.

Uno de los primeros autores en incursionar en la oralidad es Jan Vansina, que bajo un contexto de apartheit sudafricano y con las aprensiones que no viene al caso discutir, en 1965 publica Oral Tradition. A study in Historical Methodology y en 1985 Oral Tradition as History, introduciendo la utilización de la tradición oral como documento histórico analizando sus formas de transmisión, entregando una rigurosa y muy discutible clasificación específica y distintiva de los "tipos" de tradición oral, entregando una valoración para cada cual. Debemos aclarar que los análisis y estudios de Vansina son muy limitados e incorporan muy poco (o nada) la visión indígena o nativa, menos los análisis lingüísticos y la discusión que hay en torno al lenguaje "formal" impuesto por colonizadores, entre otros factores, que a nuestro parecer son importantes y decidores en estudios históricos y culturales.

Por otro lado, David Henige en 1982 determina que las tradiciones orales se vinculan estrictamente a aquellas recolecciones del pasado que son comunes o universales al conocimiento de la cultura (Henige: 1982).

Si bien esta última puede resultar más interesante, creemos que la discusión en torno al concepto de las tradiciones orales aun podría entregar más información y de forma más profunda para incorporarlas a estudios históricos. Los investigadores estaban enfocados a definir el concepto como tal, más que de ver su real valor y alcance. Con las publicaciones de David W. Cohen esta discusión toma un camino que -a nuestro parecer-enriqueció no solo la comprensión de la oralidad, sino que también la hizo plausible y útil para comprender procesos históricos determinantes en cada comunidad.
Luego de hacer una revisión de la proliferación de definiciones (Cohen, 1989) en torno a la tradición oral y de algunos estudios africanos, comprende que hay diferentes formas narrativas, y que se puede alcanzar un mayor conocimiento del pasado si se deja expresar libremente al entrevistado, más que recolectar fragmentos en función a formas de narrativa formales (Cohen, 1972).

Y bajo esta óptica, podemos observar las tradiciones orales, los testimonios y cualquier forma narrativa del pasado desde el mismo discurso en el presente. En este sentido poco nos importa su forma verbal, sino más bien entender el valor histórico que ellas contienen en sí, al traspasarse de generación en generación -bajo formas narrativas fijas (como poesías y canto) o no (como leyendas y mitos)- y el cambio de paradigma que esto supone, donde el énfasis ya no está dado por la "forma" verbal, sino más bien por su contenido, el que trae consigo un contexto, es manifestado con una expresión verbal o no verbal que en definitiva se vuelve la mirada a su valor cultural.

Esto nos señala que no podemos limitar este campo de la "oralidad" solo a las formas narrativas del discurso, ya que posiblemente encontremos nuevas formas de transmisión oral que tanto en su formación como en sus modificaciones dependerán del grupo humano y el contexto, denotando en ello procesos y sistemas valiosos de analizar y comprender para construir el pasado. Bajo esta perspectiva, en adelante hablaremos simplemente de oralidad para referirnos a cualquier forma narrativa hablada.

Hemos de entender entonces que el testigo es una especie de contenedor de la memoria y que cuando comunica esta memoria a otros (transformándose en un vehículo) forma parte de un canal de transmisión. Es muy interesante observar cómo es que la oralidad puede mantenerse relativamente intacta con el paso de los años, cómo puede también tener acepciones u omisiones dependiendo de la capacidad de memoria que adquiera la persona contenedora de esta. Aquí nos encontramos con la subjetividad, que creemos es más aporte que desventaja, porque las modificaciones y formas también dan cuenta de procesos culturales interesantes de analizar.

Respecto de esta discusión y los prejuicios que tienen los testimonios orales, Paul Thomson ha dedicado el capítulo cuarto y quinto de su texto The Voice of the Past (Thompson, 1978 [1988]), demuestra que toda memoria cual sea su origen, debe ser evaluada y comparada con otros elementos 
en virtud de que el problema no solo pasa por la veracidad, sino que también por las "omisiones".

Thompson plateó en una conferencia en la Universidade Federal de Minas Gerais en Belo Horizonte $^{5}$ lo siguiente:

(...) tenemos tanto que aprender acerca de la reconstrucción de la memoria como de los hechos mismos, y, en este caso, ambos surgen de registros orales. El problema de la memoria siempre será una cuestión fundamental para los historiadores orales, pero creo que debemos abordarlo teniendo en cuenta su doble fuerza, objetiva y subjetiva, que contiene la historia oral (Thompson, 2003: 29).

En definitiva, señala que esa subjetividad tan enjuiciada de los testimonios también entrega conocimiento y ese es un gran valor para incorporar en los estudios históricos. La historia es también una instancia de "creación de memorias" y estas son útiles para las localidades, porque dotan de sentido el pasado, forjan identidad y conducen a un presente mucho más comprensible. Si se logra establecer vínculos reales desde la cultura local (ya sea mediante la observación, aplicación de entrevistas, estadísticas u otras tácticas metodológicas) y la historia local incorporando la memoria en la oralidad, es muy probable que nos acerquemos justamente a lo que buscamos: una historia representativa.

Por historia oral entendemos todos los testimonios de individuos insertos en un sistema cultural grupal que se vinculan con su territorio en el más amplio aspecto. En este sentido concordamos con Thompson quien,

...se inclina por una definición amplia de "historia oral" como la interpretación de la historia, las sociedades y las culturas en proceso de cambio a través de la escucha $\mathrm{y}$ registro de las memorias y experiencias de sus protagonistas, y por lo tanto no me parece apropiado concebirla ni como método de trabajo minuciosamente determinado y con reglas fijas ni como una subdisciplina separada (Thompson, 2003:15).

En definitiva, podemos hacer una historia mucho más representativa de una comunidad utilizando las tácticas de la oralidad e historia oral ${ }^{6}$, entendiendo que esta no es precisamente una nueva disciplina dentro de la historia, sino más bien una posibilidad válida de incorporar en el discurso. Thompson plantea que The challenge of oral history lies partly in relation to this essential social propose of History (Thompson, 1978 [1988]: 3), el solo hecho de escuchar a la comunidad nos sitúa frente a ella desde una perspectiva mucho más sensible. Escuchar a gente local hace incluir en el discurso histórico percepciones desde diversos puntos de la sociedad, comprendiendo que ese conocimiento es mucho más completo y democrático, si se quiere.

Planteado todo lo anterior, podemos instalarnos con una base teórica que permite definir y situar las tácticas metodológicas, las que procederemos a describir.

\section{La cultura del presente y del pasado}

Creemos importante -más que describir y definir-discutir y reflexionar en torno a conceptos descritos y por lo mismo muchas veces mal utilizados, que tienen directa relación con comprender el sistema local de un grupo humano, de tal manera que sobre esta base teórica podamos trabajar las tácticas metodológicas que buscan rescatar la memoria desde la oralidad.

Mucho se ha dicho sobre cultura, creemos que la discusión hoy se debe abordar desde el punto de vista de la experimentación teórica y, por consecuencia, su aplicación. No podemos dejar de mencionar la propuesta que ha hecho Geertz, cuando plantea que la cultura es:

\section{(...) entendida como sistemas de signos interpretables (...), la cultura no es una entidad, algo a que puedan atribuirse de manera casual acontecimientos sociales, modos de conducta, instituciones o pro- cesos sociales, la cultura es un contexto dentro del cual pueden describirse todos esos fenómenos de manera inteligible, es decir, densa (Geertz, 1973 [2006]: 27).}

Ya que con esto volcamos el enfoque desde definir conceptos hacia pensar los conceptos y en ello buscar-de forma reflexiva y analítica- un real sentido a la cultura y no un sinfín de significados como las que recopilan y analizan A.L. Kroeber y Clyde Kluckhohn en su valioso texto Culture; $a$ Critical Review of concept and definition (Kroeber 
A.L. and Kluckhohn, 1952). A decir verdad, el aporte entregado por Kroeber y Kluckhohn al evidenciar ello pasa por presentar tres ideas que creemos importantes. La primera dice relación con la capacidad que tienen los investigadores de crear conceptos en las Humanidades para situar los análisis limitándolos a un radio de acción específico, lo que creemos es muy importante, pero conservador entendiendo que lo que aquí proponemos es ir más allá de los límites tanto disciplinarios como conceptuales. La segunda idea es que dicha revisión evidencia las coherencias, incoherencias y choques entre distintos autores que buscan estructurar lo humano bajo nociones herméticas, lo que es indeterminado en sí mismo, ya que una de las condiciones fundamentales $-\mathrm{y}$ que muchas veces olvidamos- es evidenciar la flexibilidad y dinamismo propio de los grupos humanos a los que se les adjudica una u otra cultura. En otras palabras, las modificaciones de este concepto en particular se han ido articulando ya sea por la evolución del pensamiento intelectual respecto del análisis de fenómenos y, por otro, la dificultad propia que supone el crecimiento de las sociedades en los últimos tiempos. Y finalmente como tercera idea se observa -y aquí evocamos también los dos puntos anteriores- la necesidad actual de crear límites metodológicos ${ }^{7}$ para una u otra disciplina de las Ciencias Humanas, definiendo de alguna forma el campo de estudio en sí mismo en un intento de hacer plausible lo que inherentemente no lo es: comprendernos como seres. El texto de Kroeber y Kluckhohn también logra tensionar ideas en relación con el comportamiento del hombre, a la relación del individuo con la cultura y por sobre todo -y que creemos muy importante- pone en evidencia que la cultura es un término abstracto que intenta caracterizar a un grupo humano;

\section{Culture is an abstract description of trends toward uniformity in the words, acts, and artifacts of human groups. Like personality, culture might be conceived dynamically as the working out of the implications of certain genetic foci (Kroeber A.L. and Kluckhohn. 1952: 359).}

Ambos proponen su propio concepto de cultura, entendiendo de antemano que asumen la línea de los simbolistas al señalar:
We think culture is a product; is historical; includes ideas, patterns, and values; is selective; learned; is based upon symbols; and is an abstraction from behavior and the products of behavior (Kroeber A.L. and Kluckhohn. 1952: 308).

Efectivamente creemos junto a estos investigadores que no podemos si no acercarnos a la cultura como un producto de un algo, pero también creemos que este producto no es estático. Como concepto en sí mismo tiene incluso mayor ambigüedad que concreción. Para hablar de una cultura y luego analizarla, es necesario comprender cuáles son los aspectos que el lenguaje verbal no siempre puede abarcar. Hablamos de ese sentir de la cultura ${ }^{8}$; que puede o no identificar a un individuo (creemos que allí se evidencia una de las grandes diferencias entre el concepto cultura e identidad), pero que sí es reconocible por un grupo humano. Para ejemplificar lo anterior, podemos decir que no es lo mismo ver al Ballet Folclórico Nacional representando el baile tradicional de la Tirana, en un escenario y con cuerpos esbeltos, trajes y coreografías bien compuestas en una armonía y perfecta coordinación de la puesta en escena con la orquesta sinfónica, que un grupo de participantes de la misma fiesta de la Tirana en el norte del país en una verdadera procesión a la virgen, donde participan niños y adultos, con trajes que están más ocupados de su devoción que de la composición artística de una puesta en escena, que está lejos de tener por objetivo exhibir un baile tradicional a un grupo selecto de personas en un teatro.

Cassirer advertía la importancia del estudio de las formas simbólicas en el campo de la Filosofía aplicada a la Antropología. Este filósofo alemán contribuye de manera significativa en la comprensión de los símbolos humanos, pues al establecer la existencia de un sistema de formas simbólicas incorpora el sentido sistémico en la obra del hombre, cambiando así el paradigma estructuralista e incorporando aquello propio de los sistemas: el constante movimiento.

Por tanto es ese dinamismo propio de las sociedades y la capacidad de un grupo humano de generar sistemas simbólicos particulares desde los cuales uno puede comprender la lógica del pensamiento de uno u otro grupo humano, comprender eventos históricos y cómo estos se fueron perpetuando a lo largo del tiempo en la cultura. Al respecto, creemos junto a Cassirer que: 
La característica sobresaliente y distintiva del hombre no es su naturaleza metafísica o física sino su obra. Es esta obra, el sistema de las actividades humanas, lo que define y determina el círculo de la humanidad. El lenguaje, el mito, la religión, el arte, la ciencia y la historia son otros tantos "constituyentes", los diversos sectores de este círculo (Cassirer, Ernst. 1997 [1944]: 108).

Cassirer desde ya entiende que el hombre es el creador de su propio entorno, es quien modela su medio natural para crear un sistema que él mismo dota de significación. Es este sistema el que intentamos describir e interpretar. La complejidad no pasa por buscar una estructura común en toda la humanidad, sino comprenderla y observar cuáles fueron esos detalles que dieron pie a la formación de ciertos elementos del cuerpo simbólico compartido en un grupo humano en particular, desde donde se formula y plantea una cultura y surge lo que denominaremos la historia de una mentalidad común, entendiendo esta última desde la diversidad que supone un grupo humano. Las estructuras del lenguaje y de significaciones pueden entregarnos mucha información respecto del cómo y por qué un grupo determinado reacciona de una manera frente a un hecho y no de otra.

Es en esta dirección que proponemos analizar las variables tiempo, espacio y mentalidades que formularon un cuerpo simbólico en particular y dieron paso a modificaciones a lo largo del tiempo. Ese cuerpo simbólico es reconocible por todos, lo que no significa que todos se identifiquen con él de manera íntima; el solo hecho de ser reconocibles ya está marcando la diferencia, pues creemos junto a Said que:

La cultura siempre es histórica, y siempre está anclada en un lugar, un tiempo y una sociedad determinada. La cultura siempre implica la concurrencia de diferentes definiciones, estilos, cosmovisiones e intereses en pugna. Además, las culturas pueden volverse oficiales y ortodoxas -como en los dogmas de sacerdotes, burócratas y autoridades seculares- o pueden tender hacia lo heterodoxo, lo no oficial y lo libertario. En ambos casos, sin embargo, lo interesante de una cultura es su relación con otras culturas y no solo su interés en ella y su grandeza9.

La cultura es histórica y muchas veces son los quiebres históricos, acontecimientos importantes, los decisorios para observar cómo es que una cultura reacciona o se levanta frente a hechos tan traumáticos como un golpe de Estado o un terremoto, por ejemplo. Es ese levantamiento el que reafirmará o modificará su cuerpo simbólico y su cohesión.

Efectivamente, podemos plantear aquí que si hemos de analizar la cultura que se desarrolló o desarrolla en un lugar, no podemos olvidar que la cultura, ni por muy local que sea, está conformada por diversas corrientes ideológicas que establecen dinamismos y tensiones particulares y que por muy distintas que se vean, conviven y se validan entre sí. Es por ello que la oralidad nos entrega una versión distinta que la documentación formal escrita, sobre todo cuando nos referimos a grupos humanos que han vivido procesos de dominación, como veremos más adelante.

Hay que entender que no existe cultura pura ni estática, por lo mismo observadas desde ciertas dinámicas culturales se vinculan más a los procesos históricos que se viven a niveles macros y el cómo estos repercuten en lo local, pues en ellos veremos las adaptaciones y respuestas que se manifiestan dentro del grupo humano.

A nuestro parecer, un sistema cultural se establece principalmente gracias a tres elementos fundamentales que se articulan generando una concatenación probablemente simultánea, estableciendo los códigos y sistemas simbólicos. Estos elementos son: territorio, grupo humano e historia común.

El territorio entrega los recursos, el clima, la flora y fauna, desde donde se desarrolla la vida cotidiana, la que se construye en función a la organización social y cultural que adopta el grupo humano que reside en ese lugar. Este puede ser oriundo del lugar o extranjero, pero logra una suerte de cohesión sistémica en tanto se adapta a los códigos locales, códigos que también pueden ser modificados por la llegada de otras culturas. Este es el elemento más permeable de todos, es en el grupo humano donde percibimos la cultura y las diversas corrientes ideológicas que a pesar de ser distintas, siguen perteneciendo y formando parte de esta. Será la cultura uno de los sistemas más importantes que crearán y modelarán las representaciones de este grupo humano que se adaptará, que cambiará 
y que transmitirá u olvidará sus tradiciones, gran parte de esos procesos podemos conocerlos desde la oralidad, entre otros.

De alta relevancia son los aconteceres históricos, las decisiones políticas, entre otros acontecimientos determinantes que provocan modificaciones tanto en el grupo humano como en el territorio y que a su vez son altamente susceptibles a influencias de procesos mayores de historia regional y nacional. Esos acontecimientos que ocurren a nivel mundial afectan indistintamente a los diversos territorios de forma directa o indirectamente. A modo de ejemplo, entendemos por estos acontecimientos guerras, invenciones industriales-tecnológicas, entre otros eventos vinculados a la economía y política mundial.

En definitiva, la cultura es en sí misma un mecanismo desarrollado por el hombre para adaptarse al medioambiente natural, social y tecnológico.

Si observamos esto desde lo oral, podemos entonces comprender que todos estos elementos, procesos y sistemas son comprendidos desde la verbalidad. Es en este sentido que se vuele sumamente interesante la lingüística y todo lo que desde ella se desprende. No obstante ello, no podemos profundizar en esta materia por ahora. Lo que debemos comprender es que la complejidad de la oralidad deviene desde su formación conceptual verbal hasta el contenido que transmite. Ese contenido puede ser interpretado por otros y eso en sí mismo también establece parámetros y datos valorables y determinantes para estudios culturales, los que en definitiva nos permiten observar el pasado.

\section{La importancia de lo local para entender la memoria}

Para sensibilizarnos con la propuesta metodológica que estamos insipientemente desarrollando en este artículo, debemos precisar ciertos conceptos. Creemos que los estudios histórico-culturales deben hacerse desde la concepción de lo local, entendiendo que este forma parte de circunscripciones mayores que les influyen directamente. Es en el ámbito de lo local donde se logran distinguir variantes culturales y respuestas fenomenológicas particulares y, por tanto, identitarias que se advierten en la memoria. A nuestro entender esta es la forma que vislumbramos para llegar a análisis culturales profundos desde lo oral y que eventualmente puedan entregar reales aportes al discurso histórico y a su vez - de forma asertiva-incidir incluso en la toma de decisiones políticas, comprendiendo a cabalidad las necesidades locales.

La formación de matices particulares dentro de los mismos grupos humanos, matices de reconocimiento y valoración única (quizás con elementos causales específicos -hablamos de territorio, recurso, espacio urbano y capital humano-) es cercano a la distinción de unos con otros y de paso a las nociones de identidad.

Debemos considerar que si vamos a trabajar la memoria local desde la oralidad, el análisis interpretativo lleva a parámetros mucho más profundos que el solo hecho de describir y ordenar la trama simbólica bajo parámetros reconocibles. En este sentido creemos fundamental observar y analizar de forma conjunta el contexto en todas sus formas, porque la interpretación obliga a observar los acontecimientos históricos sociales en espacios y momentos determinados, para cifrar de forma plausible el paisaje de investigación que conduce a diversas interpretaciones de un mismo hecho. A pesar de lo amplio que pueda percibirse un estudio en esta línea, esas diversas interpretaciones pueden acotarse desde lo local, en tanto se observe de manera clara y precisa el objetivo de un estudio en particular.

Es así como nos encontramos próximos a llegar a una discusión que ha marcado enormemente este siglo; hablo concretamente de la problemática que tienen las disciplinas en tanto estas muchas veces padecen de líneas etnocentristas que, en el caso de estudios históricos-culturales, pueden verse reflejadas en las interpretaciones. Es por ello que creemos interesante tener en cuenta la obra de Edward Said (Said:2010 [1997]), quien aborda estos temas entregando a su vez interesantes ideas al respecto. El autor deja en evidencia la creación de conceptos desde una mirada imperialista en relación con una geopolítica que hemos absorbido desde el marco conceptual intelectual eurocentrista, pues es desde ahí que analizamos la oralidad. Si bien Said hace una vinculación de estos términos con la dominación colonialista, creemos que en ello hay además un valor tendiente a realzar lo local como medio de interpretación en sí mismo, observando que la diferencia entre una interpretación u otra puede radicar esencialmente en los principios de concepción estética del medio, entendiendo esto como la sensibilidad de interpretación de objetos, 
actos y quehaceres de un día a día en el campo de lo doméstico. Es decir, esa dimensión creada desde la comprensión y conciencia del medio, adjudicando significados a símbolos, se relaciona directamente a las nociones de cultura. Esto si lo utilizamos como ejercicio para construir una imagen interpretativa popular se vuelve realmente interesante, en el sentido de que muchas de esas imágenes ya construidas en las Ciencia Humanas forman parte de un canon intelectual global más bien dominado por corrientes eurocentristas, a causa del origen de las disciplinas. No obstante ello, nuevas corrientes de pensamiento iniciadas a mediados del siglo XX buscan salir de ese ello, para llegar a nuevos paradigmas más vinculados a los sistemas locales o propios. Esto se logra luego de la diversificación y explanación de otras formas de pensar. Si bien Said plantea esta problemática dirigida al Cercano Oriente, podemos percibirla también en Latinoamérica y en general a todos los lugares del mundo que fueron colonizados. Uno de los tantos factores que impera en un proceso de conquista y colonización es la imposición de la cultura del grupo humano extranjero a los otros (quienes sueles ser originarios), en una suerte de dominación que se impone por medio de diversas formas como relaciones económicas, políticas, regionales, de lenguaje, entre otros. Esto genera, de manera consciente o inconsciente, imágenes y conceptos muchas veces peyorativos o errados para con las culturas propias u originarias.

Como bien plantea Said,

(...) existen muchas representaciones, que se han posesionado en el mundo como "verdades" mas no dejan de ser meras "representaciones, y no retratos $<$ naturales $>$ " (Said, 2010 [1997]: 44).

Concordamos con Said cuando escribe:

(...) toda investigación humanística debe establecer la naturaleza de esta relación [refiriéndose a la relación política y cultural] en el contexto específico de su estudio, de su tema y de sus circunstancias históricas (Said, 2010 [1997]: 38).

Creemos que en esas variables se pueden fundar muchos razonamientos, incorporando la flexibilidad que da por una parte el contexto de lo local (geografía, historia común, grupo humano específico) $y$, por otra, el dinamismo inherente que justifica el análisis de procesos humanos y la interpretación del investigador, que por muy neutral que desee ser siempre juzga en relación con sus herramientas, sus medios y su propia experiencia. Por tanto, la modelación del actual análisis -hablo de la modelación por el intento de reunir diversas corrientes de pensamientos, para llegar a un solo objetivo: hacer un estudio histórico cultural de una localidad en particular utilizando la oralidad-se funda sobre la base de la existencia de medios para crear un estudio local, desde lo local, donde el pensamiento interdisciplinario y divergente colabora en gran medida a la interpretación de este, comprendido desde la subjetividad más íntima.

Creemos que respecto de este tema Bourdieu hace un aporte interesante:

Toda mi empresa científica se inspira, en efecto, en la convicción de que no se puede asir la lógica más profunda del mundo social sino a condición de sumergirse en la particularidad de una realidad empírica, históricamente situada y fechada, pero para construirla como "caso particular de lo posible", según las palabras de Bachelard, es decir, como una figura en el universo finito de las configuraciones posibles. (...) se trata de asir lo invariable, la estructura, en cada una de las variantes observadas (Bourdieu, 2008 [1997]: 24-25).

Si bien Bourdieu busca -debido a su formación sociológica- la estructura, esta sugiere un análisis reflexivo de una realidad local. En este sentido la "estructura" será útil a nuestro estudio siempre y cuando se entienda desde los particulares procesos culturales que se dieron a partir de acontecimientos específicos dentro del grupo humano a analizar. En esta línea creemos es determinante comprender la importancia de lo local como espacio social y simbólico.

Bourdieu propone,

(...) recoger las diferencias reales de las cuales necesita buscar el principio no en las singularidades de una naturaleza $-\mathrm{O}$ de un "alma", como dicen algunos, los orientalistas, para no nombrarlos...- sino en las particularidades de historias colectivas diferentes (Bourdieu, 2008 [1997]: 25). 
Bourdieu plantea buscar en las diferencias las particularidades indagando en la esencia de lo universal en lo particular. Esas diferencias son las que le hacen tener una visión crítica del orientalismo. No obstante ello creemos que ambas versiones son perfectamente articulables, dependerá desde dónde se aborden y cómo se interpreten las culturas. Esto lo visualizamos más como un problema disciplinario que como contradicción de contenido. La estructura que busca Bourdieu en su trabajo tiene que ver con el moldeamiento del espacio que concibe en una forma abstracta capaz de funcionar en diversos sino en todos- espacios sociales. Creemos que esta postura puede ser útil en una primera aproximación, no imposibilita que se pueda poner en cuestión la interpretación de la cultura en el discurso, que es lo que Said de alguna forma viene a revisar. Acá evidenciamos algo que las Ciencias Humanas han olvidado, que es la sensibilidad del espacio de lo íntimo en un grupo humano, eso íntimo que en Historia del Arte se busca en el análisis psicológico del artista y la Estética utiliza para comprender la obra de arte en un medio social e histórico particular. Eso que pocas veces logramos explicar con palabras o logos y que se puede captar en un canto tradicional con sus entonaciones y ritmos.

Como hemos dicho, la propuesta de este artículo es generar un espacio reflexivo que surge desde la oralidad y la memoria para entender la esfera desde y para lo local con una vista mucho más sensible de lo que acostumbramos, utilizando tácticas metodológicas como por ejemplo entregar herramientas conceptuales a los propios habitantes de la localidad de estudio para que ellos mismos puedan reflexionar acerca de su propia cultura e identidad. Ese simple ejercicio abre un mundo de posibilidades.

En definitiva, hemos de utilizar,

(...) ese principio generador y unificador que retraduce las características intrínsecas y relacionales de una posesión en un estilo de vida unitario, es decir, un conjunto unitario de elección de personas, de bienes, de prácticas (Bourdieu, Pierre. 2008 [1997]: P. 31).

De un cuerpo simbólico y de un dominio reconocible para quienes lo habitan. En este sentido, es importante entender el término Habitus ${ }^{10}$ que define Bourdieu en sus textos, más en la línea de investigación que pretende,
Renunciar a un intento de explicación de los fenómenos sociales que los entrelace en grandes texturas de causas y efectos para optar por otra que trate de explicarlos situándolos en marcos locales de conocimiento significa sustituir una serie de definidas por otras mal definidas (Geertz, Clifford. 1983 [1994]: 14).

Pero esto no podemos hacerlo sin antes comprender cuáles son estas nociones bien definidas.

Creemos que en contexto de lo local lo marginal que propicia Foucault en La arqueología del saber se vuelve parte del discurso histórico, pues entran dentro del rango geopolítico del análisis a realizar.

Nos preguntamos ¿qué es lo que pasa dentro de la esfera de lo local?, ¿cómo es que estos espacios se diferencian de otros?, ¿qué es aquello que lo hace particular?, ¿cuál de los elementos allí presentes se conjugan para crear un algo nuevo? Lo primero para abordar estas preguntas es desmembrar y desentrañar cómo se formó ese cuerpo simbólico, qué factores fueron relevantes en la formación de este. Qué es lo que percibo-yo extranjero-y lo que percibe -el yo habitante y participante-y ¿qué hay de las culturas dominantes? ¿Y de los procesos laborales?

Quizás lo primero sería llegar a ese "resultante" 11 entendiéndolo como el presente observado. Es decir, a esa cultura e identidad que ha sido formada a lo largo del tiempo, para posteriormente -y en conjunto con la documentación existente de época- indagar en la memoria por medio de la oralidad las imbricaciones culturales y el acontecer nacional para comprender la influencia y mixtura que se dan en el "resultante" -tal vez un poco por azar- en las culturas locales. En dicho proceso observar qué es lo que tomó mayor preponderancia en el cuerpo simbólico y con ello analizar qué grupo de habitantes predominó en los "otros" para analizar el pasado y determinar con él la identidad. Todo para comprender el pasado desde el presente dando como producto una historia local mucho más cercana, al ser identitaria, mucho más representativa y reconocible por sus habitantes.

\section{Hacia una historia representativa}

A nuestro entender la historia es fundamental en el momento de generar imágenes representativas de "realidades". Establecer conceptos como "realidad", supone un riesgo, ya que su teorización es 
cuantiosa y crucial; la filosofía nunca ha cesado en darle nuevas significaciones, la antropología, por su parte, lo ha utilizado infinitas veces para explicar situaciones del hombre y lograr dar un orden sistémico para su entendimiento. Si observamos la metodología tradicional de hacer histórico como lo plantea Foucault (Foucault: 2005 [1969]), podemos observar el manejo de la memoria que se genera cuando la historia se escribe solo desde un punto de vista, el que -por lo general- era extraído de los documentos ${ }^{12}$, olvidando que los acontecimientos son interpretados en función a la experiencia de un grupo humano que lo escribe. En su contraparte, la historia de las mentalidades ha frustrado lo anterior, tratando de buscar una objetividad dentro de la subjetividad que esto supone, siempre a base de las ideologías; sin duda, todas ellas realidades creadas. Al respecto Foucault señala:

La historia de las ideas, del pensamiento y de las ciencias (...) ha disociado la larga serie constituida por el progreso de la ciencia, o la teología de la razón, o la evolución del pensamiento humano; ha vuelto a poner sobre el tapete los temas de la convergencia y de la realización; ha puesto en duda las posibilidades de la totalización. Ha traído la individualización de series diferentes, que se yuxtaponen, se suceden, se encabalgan y se entrecruzan, sin que se las pueda reducir a un esquema lineal (Foucault, Michel 1969 [2005]: 12).

Quizás el enfoque más coherente a nuestro estudio está dado por la corriente fenomenológica, la que establece que no existe una realidad a priori, si no es dada por la significación que entrega el ser humano inserto en un entorno específico. Este tiene una pesada carga cultural que define al objeto o suceso, según dicho parámetro. Si profundizamos aún más, percibimos la existencia de un entramado de factores que se unifican con diversos ritmos en la percepción del sujeto frente a un hecho, a sí mismo y a su entorno. La subjetividad está presente en todos sus rincones, sin embargo se convierte en objetividad para quien percibe su realidad como real ${ }^{13}$.

Lo cierto es que existe una realidad definida y determinada por el individuo o un grupo humano que la vive; esta es reconstruida o significada por la representación del sistema de formas simbólicas ${ }^{14}$, insertándose a un sistema de valores y de ordenamientos que dependerán de un contexto social específico, de una historia común, de una cosmovisión particular en un espacio determinado. Esto se entiende aún más si se observa desde la perspectiva de Foucault (Foucault: 2008 [1966]; 2005 [1969]; 2008 [1975]) y de Geertz (Geertz, 1994 [1983]).

Lo anterior se formula a base de la experiencia individual y social; en otras palabras, las reacciones que ha tenido un grupo humano al enfrentarse a ciertos acontecimientos cruciales dentro de su propia historia, suponen comportamientos específicos que guardan relación con los condicionamientos determinados por la cultura en que se desarrolla el sujeto.

En efecto, Mocovici (Moscovici:_1891), psicólogo social francés, relaciona la realidad objetiva del sujeto, tras la fusión del sujeto y objeto; donde la representación siempre es algo-significativo- para alguien, y la división entre sujeto/objeto no puede abordarse por separado; pues un objeto no es tal, sin la significación dada por el sujeto. Un estudio interesante al respecto es el de Chartier (Chartier: 1999 [1990]), quien analiza la sociedad de la época moderna observando la cultura desde las apropiaciones que esta va generando a lo largo del tiempo.

La discusión sobre la inserción del otro, como sujeto social dominador y las modificaciones culturales que ello implica para la consolidación de una identidad particular se vuelve fascinante, para ello se utilizarán las variables y factores específicos, guiándonos por las teorías que presenta Geertz (Geertz, 2006 [1973]), Todorov (Todorov, 2012 [1982]), Said (Said, 2002 [1997]), Elías (Elías: 1989) y Bordieu (Bordieu, 2012 [1997]).

En resumidas cuentas, intentamos entender el pasado desde la memoria recabada desde lo oral para escribir la historia de una localidad desde su dimensión cultural, espacial y temporal; aspirando de esta forma llegar a lo más cercano de la representatividad de un grupo humano, o al menos evidenciar el cómo estos habitantes perciben dicha representatividad.

Dejamos en claro que el uso de la oralidad no elimina ni desvaloriza la revisión documental, por el contrario, creemos son complementarias, y la comparación, descripción o triangulación de ambas, posiblemente se acerquen un poco más a la realidad local. Por lo mismo, es necesario realizar una revisión documental y bibliográfica para ver los puntos de vista que por lo general pertenecerán a la cultura dominante, lo que posteriormente contrastaríamos e incrementamos con observaciones e 
información que captamos en el trabajo de campo con los testimonios.

La representación, que básicamente es la imagen ideada de sí mismos o ellos mismos es la que se examina en el tiempo, para ello se requiere definir períodos que por lo general deben ser amplios, y más que definir ciclos periódicos, hay que determinar los quiebres históricos que frecuentemente son altamente reconocibles.

Para llegar a la representatividad hay que crear actividades que desde un método inductivo o dialéctico se puedan recolectar sus propios pensamientos e impresiones respecto de sí mismos $\mathrm{y}$ de su entorno, porque si hemos de tener algo claro en todo esto, es que la cultura está presente en la vida cotidiana del ser humano que se desarrolla, consolida y modifica con el tiempo, y que le pertenece. Para ejemplificar esto, podemos decir que el trabajo se asemeja más al realizado por los facilitadores.

Por otro lado, no es posible separar espacio, tiempo y grupo humano; menos lo cotidiano de lo organizacional o práctico. Por lo mismo creemos que la etnometodología ${ }^{15}$ puede ser otra herramienta válida para este tipo de investigación, ya que la vida cotidiana en sí misma es un espacio de conocimiento, aprendizaje y reflexión.
Esta es la forma más cercana que vislumbramos para estudiar la memoria de las localidades y desde ahí sistematizar la información en un discurso histórico representativo. El que, entre otras cosas, aporta al reconocimiento y valoración de los grupos humanos forjando identidad.

En definitiva, podemos concluir que identificamos una utilidad práctica de la historia cuando esta incorpora la memoria y la oralidad en tanto estas la sitúan en su contexto social, y es en este sentido donde creemos que el aporte de la historia representativa aquí planteada -es decir, una historia que incorpora metodologías inclusivas-proporciona infinidad de posibilidades tanto de investigación como de su uso, ya sea para valorizar el sentido de la cultura local como para indagar más profundamente en el patrimonio de un grupo humano, el que puede utilizarse, entre otras cosas, en realzar el respeto mutuo dotando de insumos concretos como por ejemplo, hacer valer los DD.HH., en todos sus aspectos. Las tomas de decisiones (por sobre todo políticas) deben comenzar por comprender la historia común, una historia real de quienes habitan, por tanto y en este sentido, la propuesta metodológica acá planteada debe necesariamente abordarse desde lo local teniendo en consideración los alcances y limitaciones que ello conlleva.

\section{Referencias Citadas}

Berger y Luckman.

2001 [1968] La construcción social de la realidad. Amorrortu editores: Buenos Aires.

Bourdieu, Pierre

1008 [1997] Capital cultural, escuela y espacio social. Siglo XXI editores: Buenos Aires.

Cassirer, Ernst.

1997 [1944] Antropología Filosófica. Fondo de Cultura Económica: México.

Cohen, David William

1972 The historical tradition of busoga, Mulama and Kintu. Clarendon Press: Inglaterra.

Cohen, David William

1994 The combining history, University of Chigago press: USA.

Cohen, David William

1989 Undefining the oral tradition. En Ethnohistory 36 (winter, 1989) 1: 9-17.

Elías, Norbert

1989 Resumen: Bosquejo de una teoría de la civilización. Fondo de Cultura Económica: México.

Foucault, Michel

2005 [1969] La Arqueología del Saber. Siglo XXI Editores: Buenos Aires.
Geertz, Clifford

1973 [2006] La interpretación de las Culturas. Editorial Gedisa: España.

Geertz, Clifford

1994 [1983] Conocimiento Local. Paidós: Barcelona.

Henige, David

1982 Oral Historiography. Logma: London.

Hobsbawm, Eric y Ranger, Terence

2002 [1983] La Invención de la tradición. Crítica Barcelona: Barcelona.

Hofmeyr, Isabel

1994 We spend Our years as a tale that is told. Oral historical narrative in South African Chiefdom. Witwatersrand University Press: Johanesbrugo.

Kroeber A.L. and Kluckhohn

1952 Culture A critical review of concept and definition. Vintage Book: New York.

Moscovici, Serge

1891 Psicología de las minorías activas. Morata: Madrid.

Peker, Robert y Thompson, Alistair

1998 The oral history reader. Routledge: Londres.

Said, Edward

2005 [2001] Cultura, identidad e historia. En Teoría de la Cultura, un Mapa en Cuestión. Editado por SChoröder, Gerhart y Breuninger, Helga (Compiladores), Fondo Cultura Económica: Buenos Aires. 
Said, Edward

2000 [1997] Orientalismo. Debolsillo: España.

Slim, Hugo y Thompson, Paul

1994 Listen for a Change. Panos Institute New Society Publisher, Limited: Londres.

Thompson, Paul

1988 [1978] The voice of the past. Oxford Univeristy Press: Gran Bretaña.
Thompson, Paul

2003/2004 Historia oral y contemporaneidad. Anuario N $^{\circ} 20$ 2003/2004, P. 15-34. HomoSapiens Ediciones, Argentina.

Todorov Tzvetan.

2012 [1982] La Conquista de América. El problema del otro. Siglo XXI Editores: Argentina.

\section{Notas}

1 Una interesante lectura al respecto es la de Hobsbawm, Eric y Ranger, Terence (2002 [1983]) La Invención de la tradición. Crítica Barcelona: Barcelona.

2 Para mayor comprensión véase: Peker, Robert y Thompson, Alistair. 1998. The oral history reader. Routledge: Londres; Thompson, Paul 1988 [1978] The voice of the past. Oxford Univeristy Press: Gran Bretaña; Slim, Hugo y Thompon, Paul. 1994. Listen for a Change. Panos Institute New Society Publisher, Limited: Londres. Y por último sugerimos la lectura de Hofmeyr, Isabel. 1994. We spend Our years as a tale that is told. Oral historical narrative in South African Chiefdom. Witwatersrand University Press: Johanesbrugo.

3 No estamos del todo de acuerdo respecto de denominar la Historia Social como una nueva categoría, porque la Historia siempre ha sido social, ya que la elite también es parte de la sociedad. Sin embargo entendemos que "lo social" se refiere a las masas o al pueblo, y es lo que acá denominamos como historia representativa.

4 Si se quiere indagar en las primeras concepciones de la historia oral, véase el capítulo "Historian and Oral History", en Thompson, Paul 1988 [1978] The voice of the past: Oxford Univeristy Press: Gran Bretaña.

5 Historia oral y contemporaneidad. ANUARIO $\mathrm{N}^{\circ} 20$ 2003/2004, P. 15-34. HomoSapiens ediciones, Argentina.

6 Que tomaremos prestadas de la Sociología y la Antropología.

7 A modo de ejemplo, son contadas las ocasiones en que vemos utilizar el método de la observación antropológica en estudios históricos.

8 Hablamos del sentir de la cultura refiriendo a todas las sensaciones que esta produce generalmente dado su propio condicionamiento. Freud en su artículo Mal estar de la cultura (1930) establece que la cultura controla los impulsos sexuales y agresivos del hombre. Se hace mención de este texto ya que es uno de los pocos que hace alusión al sentir y si nos abstraemos de la lógica freudiana, podemos dar cuenta de que la cultura también contiene elementos sensibles que son adquiridos por su grupo y que -cual sea la causa- la cultura misma puede producir un sentimiento de arraigo en su grupo que quizás se vincule también a lo familiar. Ese sentir es el que queremos de alguna forma evidenciar y analizar, pues creemos que en él radica gran parte el sistema de permanencia de la cultura en el transcurso del tiempo, entendiendo la permanencia como un sistema de constantes movimientos y dinamismos.

9 Said, Edward 2005 [2001]. Cultura, identidad e historia. En Teoría de la Cultura, un Mapa en Cuestión. Editado por SChoröder, Gerhart y Breuninger, Helga (Compioladores), pp. 37-53. Fondo Cultura Económica: Buenos Aires.

10 Habitus, básicamente es un concepto que Bourdieu trae desde la antigua filosofía aristotélica, para denominar a todo aquello que refiere a los valores, estilos de vida, costumbres y expectaciones de un grupo humano que las adquiere en el día a día. De alguna forma es el resultante de la complejidad que decanta desde la objetividad de la estructura social en el nivel individual subjetivo. Entendido de otra forma, desde el habitus podemos describir la relación del individuo con su entorno.

11 Entendemos como "resultante" al cuerpo simbólico construido desde acumulación residual de procesos, experiencias y fenómenos socioculturales que contemplan una dinámica constante y una resignificación simbólica permanente.

12 Documentos que fueron escritos por los dignatarios de época. Ellos claramente forman parte de un sistema de imposición tanto de idioma como de leyes y cultura en su generalidad. En este sentido es lógico que los documentos son una fuente de suma importancia. El tema aquí es el cómo utilizamos estos documentos y cómo los interpretamos.

13 Al respecto: Berger y Luckman 2001 [1968], La construcción social de la realidad. Amorrortu editores: Buenos Aires. sobre todo el capítulo I titulado Los fundamentos del conocimiento en la vida cotidiana. Asimismo, Le Certeau, Michel 2000 [1990], La invención de lo cotidiano. Universidad Iberoamericana: México.

14 Al respecto ver: Cassirer, Ernst 1997 [1944], Antropología Filosófica. Fondo de Cultura Económica: México.

15 Concepto acuñado en Garfinkel, Harold. 2006. Estudios en Etnometodología. Anthropos: España. Esta metodología incorpora el sentido práctico de la racionalidad que el ser humano utiliza en la vida cotidiana para hacer análisis sociales. 